Effect of composition on damage accumulation in ternary $\mathrm{ZnO}$-based oxides implanted with heavy ions

A. Yu. Azarov, , B. G. Svensson, , A. Hallén, , X. L. Du, and, and A. Yu. Kuznetsov

Citation: Journal of Applied Physics 108, 033509 (2010); doi: 10.1063/1.3467532

View online: http://dx.doi.org/10.1063/1.3467532

View Table of Contents: http://aip.scitation.org/toc/jap/108/3

Published by the American Institute of Physics

1. Journal of Applied Physics

Save your money for your research. It's now FREE to publish with us no page, color or publication charges apply.

Publish your research in the Journal of Applied Physics to claim your place in applied physics history. 


\title{
Effect of composition on damage accumulation in ternary ZnO-based oxides implanted with heavy ions
}

\author{
A. Yu. Azarov, ${ }^{1, a)}$ B. G. Svensson, ${ }^{1}$ A. Hallén, ${ }^{2}$ X. L. Du, ${ }^{3}$ and A. Yu. Kuznetsov ${ }^{1}$ \\ ${ }^{1}$ Department of Physics, University of Oslo, P.O. Box 1048 Blindern, NO-0316 Oslo, Norway \\ ${ }^{2}$ KTH-ICT, Royal Institute of Technology, Electrum 229, SE-164 40 Kista-Stockholm, Sweden \\ ${ }^{3}$ Institute of Physics, The Chinese Academy of Sciences, Beijing 100190, China
}

(Received 25 March 2010; accepted 28 June 2010; published online 4 August 2010)

\begin{abstract}
Thin films of wurtzite $\mathrm{Mg}_{\mathrm{x}} \mathrm{Zn}_{1-\mathrm{x}} \mathrm{O}(\mathrm{x} \leq 0.3)$ grown by molecular beam epitaxy and wurtzite $\mathrm{Cd}_{\mathrm{x}} \mathrm{Zn}_{1-\mathrm{x}} \mathrm{O}(\mathrm{x} \leq 0.05)$ grown by metal organic chemical vapor deposition were implanted at room temperature with $150 \mathrm{keV} \mathrm{Er}^{+}$ions and $200 \mathrm{keV} \mathrm{Au}{ }^{+}$ions in a wide dose range. Damage accumulation was studied by Rutherford backscattering/channeling spectrometry. Results show that the film composition affects the damage accumulation behavior in both $\mathrm{MgZnO}$ and $\mathrm{CdZnO}$ dramatically. In particular, increasing the $\mathrm{Mg}$ content in $\mathrm{MgZnO}$ results in enhanced damage accumulation in the region between the bulk and surface damage peaks characteristically distinguished in the pure $\mathrm{ZnO}$. However, the overall damage accumulation in $\mathrm{MgZnO}$ layers, as well as in pure $\mathrm{ZnO}$, exhibits saturation with increasing ion dose and $\mathrm{MgZnO}$ cannot be amorphized even at the highest ion dose used $\left(3 \times 10^{16} \mathrm{Er} / \mathrm{cm}^{2}\right)$. Increasing the $\mathrm{Cd}$ content in $\mathrm{CdZnO}$ affects the saturation stage of the damage accumulation and leads to an enhancement of damage production in both Cd and Zn sublattices. (C) 2010 American Institute of Physics. [doi:10.1063/1.3467532]
\end{abstract}

\section{INTRODUCTION}

Zink oxide $(\mathrm{ZnO})$ is a direct band-gap semiconductor with numerous promising applications in the field of short wavelength optoelectronics ${ }^{1,2}$ on behalf of its wide band gap $\left(E_{\mathrm{g}} \sim 3.4 \mathrm{eV}\right)$ and large exciton binding energy $(\sim 60 \mathrm{meV})$ at room temperature. Band-gap engineering is one of the key issues for the formation of heterostructures and quantum wells, which are needed for fabrication of modern devices. It is established that the band gap of $\mathrm{ZnO}$ can be tuned up/down by alloying with other group-II oxides, such as $\mathrm{MgO}\left(E_{\mathrm{g}} \sim 7.8 \mathrm{eV}\right)$ and $\mathrm{CdO}\left(E_{\mathrm{g}} \sim 2.3 \mathrm{eV}\right.$ or smaller for indirect transitions). For example, in Refs. 3 and 4 it was reported that band-gap energy of wurtzite ternary $\mathrm{ZnO}$-based compounds can be tuned from $\sim 1.85$ to $\sim 3.9 \mathrm{eV}$ by appropriate $\mathrm{Cd}$ or $\mathrm{Mg}$ incorporation. However, the crystalline quality of the $\mathrm{MgZnO}$ and $\mathrm{CdZnO}$ films and, hence, the utilization of this material for optical applications, is challenged by a phase separation at high $\mathrm{Mg}$ and $\mathrm{Cd}$ concentrations. ${ }^{5-7}$ The phase separation is possible due to the fact that the binary components have different crystal structures ( $\mathrm{ZnO}$ has a hexagonal wurtzite (W) structure, while $\mathrm{MgO}$ and $\mathrm{CdO}$ exhibit a rock-salt (RS) cubic structure in equilibrium) demonstrating low the thermodynamic solubility of $\mathrm{RS}-\mathrm{MgO}$ and $\mathrm{RS}-\mathrm{CdO}$ in $\mathrm{W}-\mathrm{ZnO}{ }^{3}$ This also implies that the fabrication of single-phase $\mathrm{W}-\mathrm{MgZnO}$ and $\mathrm{W}-\mathrm{CdZnO}$ films with high concentrations of $\mathrm{Mg}$ and $\mathrm{Cd}$ is possible by employing metastable synthesis conditions only.

Ion implantation is a very attractive technological tool for semiconductor device processing and it can be used to introduce controllable impurity concentrations at a precise depth below the surface. However, the bombardment with energetic ions inevitably produces defects which often unde-

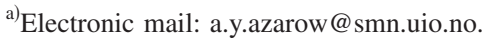

sirably affect the device performance. Concurrently, it has been shown that $\mathrm{ZnO}$ exhibits an extremely strong degree of dynamic annealing (i.e., defect migration and recombination processes occurring during the ion implantation) even at low irradiation temperatures and this material is more radiation resistant than its major rival GaN. ${ }^{2,8}$ For example, previous studies have shown that $\mathrm{ZnO}$ cannot be amorphized with heavy ions, such as Au (Ref. 8) and Bi (Ref. 9), even at very high ion doses where each lattice atom is displaced up to hundred times. Also for implantation at liquid nitrogen temperature, where the self annealing during implantation is supposed to be very low due to the slower diffusion of lattice defects, it is difficult to make the $\mathrm{ZnO}$ crystals amorphous. ${ }^{8}$ Moreover, the damage accumulation in $\mathrm{ZnO}$, as well as the removal of radiation defects during postimplantation annealing, can be strongly affected by the chemical nature of the implanted species. ${ }^{8,10}$

However, despite intensive studies of ion-beam related phenomena in $\mathrm{ZnO}$ during the last decade, ${ }^{2,8-11}$ our knowledge about mechanisms of radiation damage formation in this material is still far from being mature. Furthermore, there is very little known about radiation damage formation in $\mathrm{ZnO}$-based ternary oxides, e.g., $\mathrm{MgZnO}$ and $\mathrm{CdZnO}$. In fact the incorporation of third element in a binary compound can dramatically affect both the level of implantation disorder and the main features of damage accumulation behavior. For example, comparing to ternary GaN-based nitrides, an increase in Al concentration strongly enhances dynamic annealing processes in $\mathrm{AlGaN}$ (Ref. 12). In contrast, an increase in In content suppresses dynamic annealing processes and leads to the enhancement of damage production in InGaN films. ${ }^{12,13}$ Moreover, both AlGaN and InGaN exhibit no characteristic surface amorphization under ion bombardment in a contrast to pure GaN (Ref. 12). An understanding of 
radiation effects in $\mathrm{MgZnO}$ and $\mathrm{CdZnO}$ films is important for a successful ion-beam processing of $\mathrm{ZnO}$-based devices.

In this report, we present pioneering results indicating that the $\mathrm{Mg}$ and $\mathrm{Cd}$ composition strongly affect the damage accumulation behavior in $\mathrm{MgZnO}$ and $\mathrm{CdZnO}$ films implanted with heavy ions.

\section{EXPERIMENTAL}

About $1 \mu \mathrm{m}$ thick single-phase $\operatorname{Mg}_{\mathrm{x}} \mathrm{Zn}_{1-\mathrm{x}} \mathrm{O}(\mathrm{x}=0,0.1$, and 0.3) layers were grown by molecular beam epitaxy on $\alpha$ - $\mathrm{Al}_{2} \mathrm{O}_{3}$ substrates. Similarly $\sim 1 \mu \mathrm{m}$ thick $\mathrm{Cd}_{\mathrm{x}} \mathrm{Zn}_{1-\mathrm{x}} \mathrm{O}$ (x $=0.012$ and 0.05 ) layers were synthesized by metal organic chemical vapor deposition. According to x-ray diffraction measurements, all as-grown $\mathrm{MgZnO}$ and $\mathrm{CdZnO}$ samples exhibit single-phase wurtzite structure without any indication of phase separation. The $\mathrm{MgZnO}$ samples were implanted with $150 \mathrm{keV}{ }^{166} \mathrm{Er}^{+}$ions using an ion flux of 2.5 $\times 10^{12} \mathrm{~cm}^{-2} \mathrm{~s}^{-1}$ in a dose range of $1 \times 10^{14}-3 \times 10^{16} \mathrm{~cm}^{-2}$.

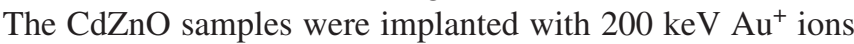
using an ion flux of $1 \times 10^{12} \mathrm{~cm}^{-2} \mathrm{~s}^{-1}$ to ion doses of 5 $\times 10^{14}$ and $5 \times 10^{15} \mathrm{~cm}^{-2}$. In order to distinguish how the $\mathrm{Cd}$ content affects the damage buildup in $\mathrm{CdZnO}$ layers, a set of control hydrothermally grown $\mathrm{ZnO}$ single crystal samples were subjected to similar implants. All implantations were carried out at room temperature at $7^{\circ}$ off the [0001] direction in order to reduce channeling.

Implantation-induced disorder was measured by Rutherford backscattering/channeling spectrometry $(\mathrm{RBS} / \mathrm{C})$ with 2 $\mathrm{MeV}^{4} \mathrm{He}^{+}$ions incident along the [0001] direction and backscattered into detectors at $170^{\circ}$ and $100^{\circ}$ relative to the incident beam direction. The $100^{\circ}$, so-called glancing-angle detector, geometry was used to provide enhanced depth resolution for examining near-surface damage accumulation. The $170^{\circ}$ geometry was used to provide enhanced mass resolution to separate signals from $\mathrm{Cd}$ and $\mathrm{Zn}$ atoms, which is needed to accurately examine the damage-depth profiles in both the $\mathrm{Cd}$ and $\mathrm{Zn}$ sublattice ${ }^{14}$ of $\mathrm{CdZnO}$ layers. Although the RBS/C technique reveals primarily interstitial (displaced) atoms it is very difficult to draw any conclusion about the type of defects presented in the sample based on RBS results alone. Even open volume defects like vacancies and vacancy clusters induce local stress and contribute to the backscattering yield during RBS/C analysis. Therefore, all RBS/C spectra were analyzed with one of the conventional algorithms ${ }^{15}$ for extracting the effective number of so-called scattering centers, conventionally referred below as "relative disorder."

\section{RESULTS AND DISCUSSION}

\section{A. $\mathrm{ZnO}$}

Figure 1 shows RBS/C spectra (a) and disorder-depth profiles (b) of $\mathrm{ZnO}$ implanted at room temperature with ${ }^{166} \mathrm{Er}^{+}$ions using different doses. The peak in the RBS/C spectra for channel numbers more then 320 is related to a signal from implanted Er atoms. It is seen from this figure that in pure $\mathrm{ZnO}$, the damage accumulates both at the surface and deeper in the bulk of the film (most pronounced for 2 $\times 10^{15}$ and $5 \times 10^{15} \mathrm{~cm}^{-2}$ ion doses). The depth where the nuclear energy loss is maximum $\left(R_{\mathrm{pd}}\right)$ and the mean pro-
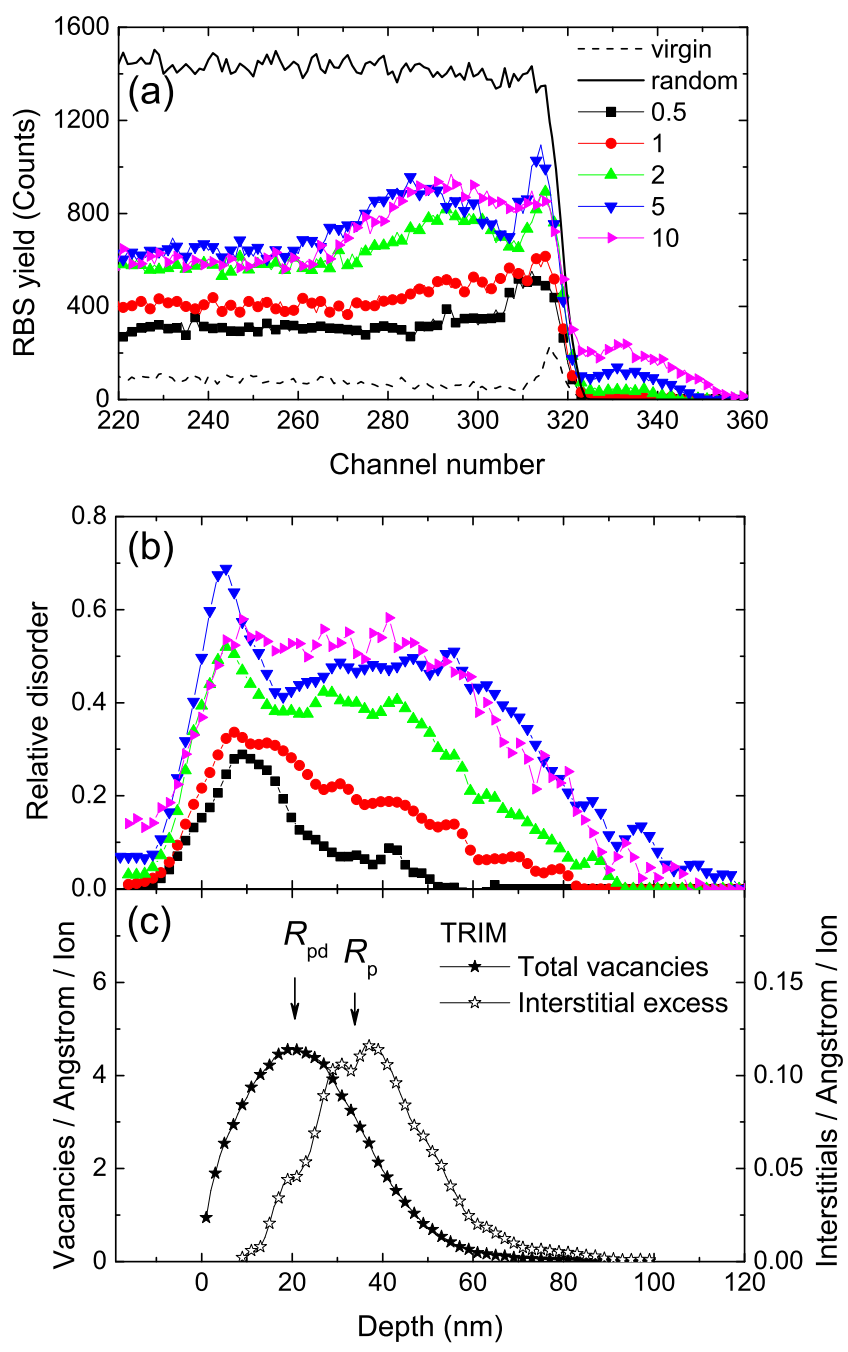

FIG. 1. (Color online) The RBS/C spectra (a) and depth profiles of relative disorder in $\mathrm{Zn}$ sublattice (b) of pure $\mathrm{ZnO}$ bombarded at room temperature by $150 \mathrm{keV}{ }^{166} \mathrm{Er}^{+}$ions with ion flux of $2.5 \times 10^{12} \mathrm{~cm}^{-2} \mathrm{~s}^{-1}$. Implantation doses (in $10^{15}$ ions $\times \mathrm{cm}^{-2}$ ) are indicated. A virgin spectrum is shown in (a) for comparison. Profiles of Er-ion-generated lattice vacancies and interstitial excesses (incident Er ions are also included) predicted by TRIM simulations are shown in (c).

jected range $\left(R_{\mathrm{p}}\right)$ of $150 \mathrm{keV}$ Er ions in $\mathrm{ZnO}$ were found at $21 \mathrm{~nm}$ and $33 \mathrm{~nm}$, respectively [see Fig. 1(c)] in accordance with TRIM code ${ }^{16}$ simulations. It is seen that the actual position of the bulk damage peak is considerably deeper than $R_{\mathrm{pd}}$ and close to $R_{\mathrm{p}}$ for the low ion doses. Furthermore, the damage in the film expands to larger depths and exhibits a saturation trend with increasing ion dose. Interestingly, there is a "valley" in the damage profile at $R_{\mathrm{pd}}$, i.e., the region where primary defects are generated, as clearly seen for intermediate doses in Fig. 1(b). Such complexity in the damage accumulation is typical for crystals with a large degree of ionicity of the chemical bonds. ${ }^{17}$

The observed damage accumulation behavior in $\mathrm{ZnO}$ may be attributed to the dynamic annealing processes in $\mathrm{ZnO}$ during ion bombardment as well as a large role of both the implanted species and the surface, which is considered to be a strong unsaturated sink for the generated mobile point defects. Indeed, an extremely pronounced radiation hardness of $\mathrm{ZnO}$ even at low temperatures suggests that the major part of 
the ion-beam-generated defects effectively annihilate during the irradiation. The minor effect of implantation temperature on defect formation in $\mathrm{ZnO}$ (Ref. 8) indicates extremely low activation of these processes. It is also well known that vacancies and interstitials are spatially separated in a collision cascade ${ }^{18}$ with an excess of interstitial close to the ion projected range and a vacancy excess closer to the surface. Evidently, dynamic annealing processes should be more efficient in the region where the spatial overlap of vacancy and interstitial distributions is larger. The effect of spatial separation of vacancies and interstitials during ion bombardment is illustrated by Fig. 1(c), which shows the depth profiles of excess interstitials (incident Er ions are also included) and ion-generated vacancies calculated with the TRIM code ${ }^{16}$ with effective threshold energies for atomic displacements of 34 $\mathrm{eV}$ and $44 \mathrm{eV}$ for $\mathrm{Zn}$ and $\mathrm{O}$ sublattices, respectively. ${ }^{19} \mathrm{Com}-$ paring Figs. 1(b) and 1(c) it is seen that a significant part of integral disorder in Fig. 1(b) is located deeper in the film (at least for the higher dose implants) correlating with the excess interstitial profile.

In its turn, the residual damage observed either at the surface or deep into the film should be formed by defects that survived the initial stages of dynamic annealing and diffused from the region where they were generated. Note that, although the long-range diffusion of generated defects should be suppressed in the damaged crystal, the bulk damage increases likely due to defects which are generated in the deep tail of their depth distribution, where dynamic annealing processes are not efficient.

Another feature seen from Fig. 1 is that the surface damage peak for the lowest ion dose is broader than that for higher doses. This interesting behavior of the surface damage peak for pure $\mathrm{ZnO}$ may be attributed to the formation of a new damage peak between the surface and "bulk" damage peak. The appearance of this intermediate damage peak, has been observed in $\mathrm{ZnO}$ for heavy ${ }^{8}$ and cluster ion ${ }^{20}$ irradiation and has been attributed to effects of high densities of collision cascades.

Thus, the damage buildup and its evolution in pure $\mathrm{ZnO}$ exhibit a complex behavior as a function of ion dose. More work and additional analysis techniques are needed to better understand the exact role of end-of-range defects, chemical effects of the implanted impurities, defect diffusion, and material decomposition in the evolution of the bulk damage peak in $\mathrm{ZnO}$. In spite the complexity may increase in ternary $\mathrm{ZnO}$-based alloys we are below presenting the results of our pioneering measurements in order to introduce the topic and initiate the discussion.

\section{B. MgZnO}

Figure 2 shows RBS/C spectra of $\mathrm{Mg}_{0.3} \mathrm{Zn}_{0.7} \mathrm{O}$ films implanted under the same irradiation conditions as the pure $\mathrm{ZnO}$ samples in Sec. III A. Magnesium at the surface can be seen as a small step in the random spectrum at channel 243, in good agreement with simulations. It is clearly seen from this figure that by increasing the $\mathrm{Mg}$ content in $\mathrm{Mg}_{\mathrm{x}} \mathrm{Zn}_{1-\mathrm{x}} \mathrm{O}$ film the damage buildup behavior is dramatically affected. As illustrated in Fig. 2 for $\mathrm{x}=0.3$, the damage buildup ap-

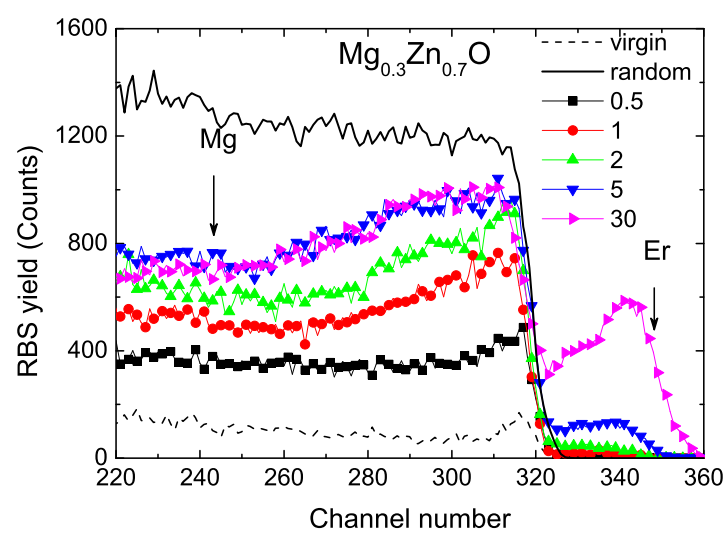

FIG. 2. (Color online) The RBS/C spectra of $\mathrm{Mg}_{0.3} \mathrm{Zn}_{0.7} \mathrm{O}$ bombarded at room temperature by $150 \mathrm{keV}{ }^{166} \mathrm{Er}^{+}$ions with ion flux of 2.5 $\times 10^{12} \mathrm{~cm}^{-2} \mathrm{~s}^{-1}$. Implantation doses (in $10^{15}$ ions $\times \mathrm{cm}^{-2}$ ) are indicated. The positions of $\mathrm{Mg}$ and $\mathrm{Er}$ at the film surface are indicated by the arrows. A virgin spectrum is shown for comparison.

pears unimodal, i.e., no clear separation between the bulk peak and the surface damage peaks is observed in contrast to that in Fig. 1(a). The effect of $\mathrm{Mg}$ content on the damage buildup is further illustrated by Fig. 3, which compares the depth profiles of relative disorder in the $\mathrm{Zn}$ sublattice for samples with different $\mathrm{Mg}$ content that are implanted to the same ion dose of $5 \times 10^{15} \mathrm{~cm}^{-2}$ (Ref. 21). It is clearly seen that an increase in the $\mathrm{Mg}$ content strongly enhances the damage accumulation in the region between the bulk and surface damage peaks, labeled with arrows in Fig. 3. However, despite of the remarkable increase in the damage production in $\mathrm{Mg}_{\mathrm{x}} \mathrm{Zn}_{1-\mathrm{x}} \mathrm{O}$ films with increasing $\mathrm{Mg}$ content, the overall damage level in $\mathrm{Mg}_{\mathrm{x}} \mathrm{Zn}_{1-\mathrm{x}} \mathrm{O}$, as well as in $\mathrm{ZnO}$, exhibits a saturation at high ion doses and does not reach the random level even for the highest ion dose used (3 $\times 10^{16} \mathrm{~cm}^{-2}$ ).

Figure 4 shows the maximum relative disorder in the bulk damage peak as a function of ion dose for all $\mathrm{MgZnO}$ samples studied ${ }^{22}$ demonstrating a clear saturation trend. Note, increasing the $\mathrm{Mg}$ content does not change the general trend of the damage accumulation in the bulk, but leads to an enhancement either in the damage production efficiency, or

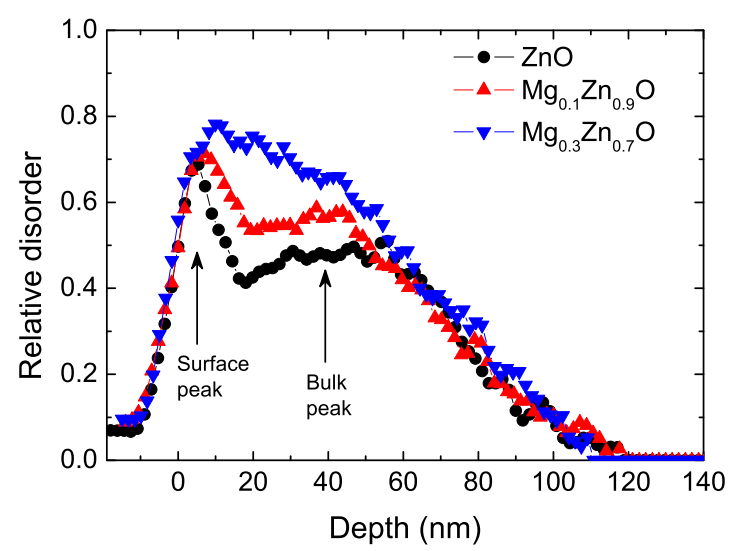

FIG. 3. (Color online) Comparison of depth profiles of relative disorder in $\mathrm{Zn}$ sublattice (extracted from $\mathrm{RBS} / \mathrm{C}$ spectra) in $\mathrm{Mg}_{\mathrm{x}} \mathrm{Zn}_{1-\mathrm{x}} \mathrm{O}(\mathrm{x}=0,0.1$, and $0.3)$ bombarded at room temperature with $150 \mathrm{keV}^{166} \mathrm{Er}^{+}$ions to an ion dose of $5 \times 10^{15} \mathrm{~cm}^{-2}$. 


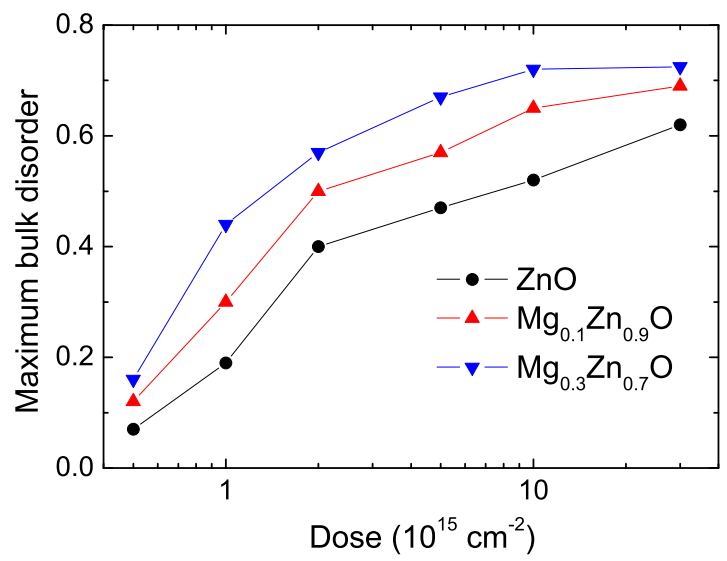

FIG. 4. (Color online) The ion dose dependence of the maximum relative disorder in the bulk defect peak in $\mathrm{Mg}_{\mathrm{x}} \mathrm{Zn}_{1-\mathrm{x}} \mathrm{O}(\mathrm{x}=0,0.1$, and 0.3$)$ bombarded at room temperature by $150 \mathrm{keV}{ }^{166} \mathrm{Er}^{+}$ions.

the damage saturation level from 0.45 to 0.7 for $\mathrm{ZnO}$ and $\mathrm{Mg}_{0.3} \mathrm{Zn}_{0.7} \mathrm{O}$, respectively. Importantly, in spite of increasing disorder no amorphization is detected in heavy ion implanted $\mathrm{Mg}_{\mathrm{x}} \mathrm{Zn}_{1-\mathrm{x}} \mathrm{O}(\mathrm{x} \leq 0.3)$, which indicates that a strong dynamic annealing process takes place.

Previous studies of defect microstructure in ionimplanted $\mathrm{ZnO}$ revealed that the bulk damage peak may be attributed to a high density of stable planar defects in addition to defect clusters. These planar defects (stacking faults) are parallel to the basal plane of the $\mathrm{ZnO}$ wurtzite structure. ${ }^{8,23}$ The similarity of damage accumulation behavior in $\mathrm{ZnO}$ and $\mathrm{MgZnO}$ may indicate the same nature of the disorder appearing in the bulk of the films. However, the disorder enhancement in the region between the bulk and surface damage peaks with increasing $\mathrm{Mg}$ content may indicate changing surface-defect interaction conditions comparing to that in pure $\mathrm{ZnO}$. It is important to note that the damage level at the surface is almost independent on the $\mathrm{Mg}$ content and also exhibits a saturation effect.

Considering the aspects that may influence the results in Fig. 3 we may mention strain and phase stability effects. First, strain-induced effects originating from the lattice mismatch between a sapphire substrate and a film may potentially influence the damage accumulation behavior in $\mathrm{Mg}$ $\mathrm{ZnO}$. However, it has been shown that $\mathrm{MgZnO}$ films exhibit relatively small alteration of the lattice parameters with a variation in $\mathrm{Mg}$ content used in our experiments. ${ }^{3}$ Therefore, strain-induced effects should not affect the damage accumulation in $\mathrm{MgZnO}$ in the first place. Second, the enhanced damage production in $\mathrm{MgZnO}$ films may be also related to the phase instability of this material during ion bombardment. Indeed, as it has been mentioned in Sec. I, W-MgZnO films are metastable at high $\mathrm{Mg}$ content, so that $\mathrm{W}-\mathrm{ZnO}$ and RS-MgO may potentially segregate during the implantation. It is seen from Figs. 3 and 1(c) that the enhancement of damage production occurs at the depth of $R_{\mathrm{pd}}$, i.e., in the region where nuclear energy loss of impinging atoms is at maximum. Evidently, the phase separation is more likely to occur in the regions where the defect generation rate is maximized and this mechanism may be more pronounced for the bombardment of $\mathrm{MgZnO}$ with heavier ions, which produce denser collision cascades.

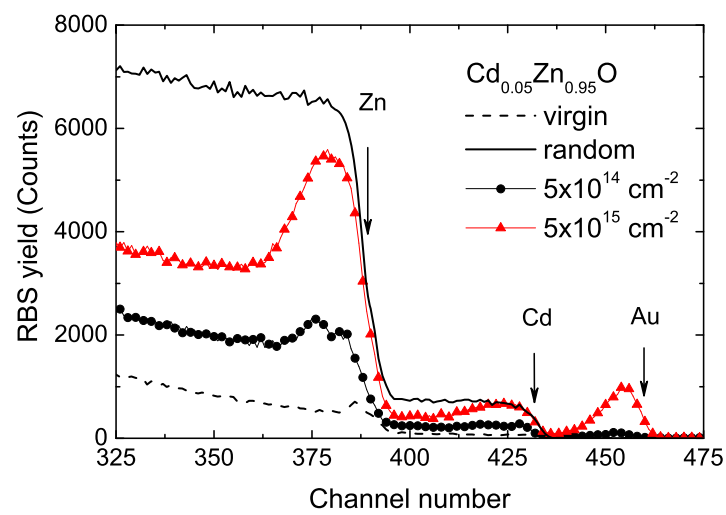

FIG. 5. (Color online) The RBS/C spectra of $\mathrm{Cd}_{0.05} \mathrm{Zn}_{0.95} \mathrm{O}$ bombarded at room temperature with $200 \mathrm{keV} \mathrm{Au}{ }^{+}$ions to two different ion doses as indicated in the legend. The positions of $\mathrm{Cd}, \mathrm{Zn}$, and $\mathrm{Au}$ at the film surface are indicated by the arrows. The virgin spectrum is also shown for comparison.

Further, the damage accumulation in $\mathrm{MgZnO}$ layers may be also affected by the initial crystal quality. The minimum channeling yield is 3\%, 5\%, and $6 \%$ for the as-grown $\mathrm{ZnO}$, $\mathrm{Mg}_{0.1} \mathrm{Zn}_{0.9} \mathrm{O}$ and $\mathrm{Mg}_{0.3} \mathrm{Zn}_{0.7} \mathrm{O}$ samples, respectively, which indicates a lowering of the crystal quality of the material with increasing $\mathrm{Mg}$ concentration. These initially presented defects may potentially act as additional nucleation sites for the defect growth and/or affect diffusion length of primary defects and, hence, give some contribution to the damage enhancement in material with increasing the $\mathrm{Mg}$ content.

It is important to note that the damage accumulation in $\mathrm{MgZnO}$ is also different from that occurring in $\mathrm{MgO}$ (Refs. 24 and 25). Indeed, although the disorder in $\mathrm{MgO}$ exhibits typical feature for the ionic crystals with damage saturation, the ion-beam-produced damage in $\mathrm{MgO}$ accumulates preferentially in the bulk. Furthermore, the damage saturation level in $\mathrm{MgO}$ is lower than that for $\mathrm{ZnO}$ and $\mathrm{MgZnO}$ (Ref. 25). Such damage accumulation behavior may be attributed to the lower ionicity of $\mathrm{Zn}-\mathrm{O}$ bonds in comparison to that of $\mathrm{Mg}-\mathrm{O}$. Indeed, according to empirical bond-type criterion, ${ }^{17}$ the resistance to amorphization increases with increasing the ionicity of chemical bonds. Phillip's ionicity of $\mathrm{Mg}-\mathrm{O}$ and $\mathrm{Zn}-\mathrm{O}$ bonds are 0.84 and 0.61 , respectively. ${ }^{26}$ However our results support that this criterion cannot be directly applied for the prediction of damage buildup behavior in ternary compounds.

Finally, we note that the $\mathrm{Mg}$ content also affects the substitutional fraction of implanted ions. For example, increasing the $\mathrm{Mg}$ content from $0 \%$ to $30 \%$ leads to reduction in the fraction of incorporated Er atoms in substitutional sites from $\sim 35 \%$ to $10 \%$ for an ion dose of $5 \times 10^{15} \mathrm{Er} / \mathrm{cm}^{-2}$. Thus, decreasing of substitutional Er is correlated with damage production enhancement which occurs in $\mathrm{MgZnO}$ alloy with increasing the $\mathrm{Mg}$ content.

\section{C. $\mathrm{CdZnO}$}

Figure 5 shows RBS/C spectra illustrating the damage buildup in $\mathrm{Cd}_{0.05} \mathrm{Zn}_{0.95} \mathrm{O}$ films implanted with $200 \mathrm{keV} \mathrm{Au}^{+}$ ions using two different ion doses as indicated in the legend. The positions of $\mathrm{Cd}, \mathrm{Zn}$, and $\mathrm{Au}$ at the film surface are indi- 


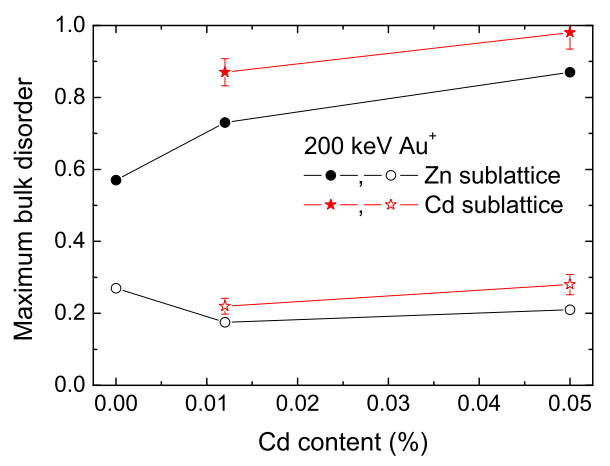

FIG. 6. (Color online) Maximum relative disorder in $\mathrm{Zn}$ (dots) and $\mathrm{Cd}$ (stars) sublattice as a function of $\mathrm{Cd}$ content $(\mathrm{x})$ in $\mathrm{Cd}_{\mathrm{x}} \mathrm{Zn}_{1-\mathrm{x}} \mathrm{O}$ films implanted at room temperature with $200 \mathrm{keV} \mathrm{Au}$ ions to $5 \times 10^{14} \mathrm{~cm}^{-2}$ (open symbols) and $5 \times 10^{15} \mathrm{~cm}^{-2}$ (closed symbols).

cated in the figure by arrows. It is seen from Fig. 5 that the $\mathrm{Au}$ bombardment leads to damage accumulation in both $\mathrm{Zn}$ and $\mathrm{Cd}$ sublattices and the disorder increases with the ion dose. It is also seen that for the higher dose (5 $\times 10^{15} \mathrm{~cm}^{-2}$ ) the damage level in the $\mathrm{Cd}$ sublattice reaches the random RBS level which indicates that all $\mathrm{Cd}$ atoms are displaced in the near surface region. On the other hand, our estimations revealed that damage level in the $\mathrm{Zn}$ sublattice is lower than that for the $\mathrm{Cd}$ sublattice. Thus, the damage accumulation rates in $\mathrm{Cd}$ and $\mathrm{Zn}$ sublattices in $\mathrm{CdZnO}$ are not equal. Such damage accumulation behavior may be attributed to lower effective diffusivity of Cd interstitials in comparison to that of $\mathrm{Zn}$ and, consequently, lower efficiency of dynamic annealing in $\mathrm{Cd}$ sublattice. This result is in strong contrast to the ternary compounds based on $\mathrm{GaN}$ such as InGaN where the implantation disorder proceeds at essentially the same rate. ${ }^{13}$ In addition, it should be pointed out that the RBS results also revealed that all Au atoms are localized in nonsubstitutional sites for both $\mathrm{ZnO}$ and $\mathrm{CdZnO}$ (not shown); this holds even for the low ion dose, in a contrast to the Er implantations in $\mathrm{ZnO}$ as discussed in Sec. III B.

The effect of Cd content on the damage buildup is summarized in Fig. 6 showing the maximum bulk disorder in both $\mathrm{Zn}$ and $\mathrm{Cd}$ sublattices as a function of the $\mathrm{Cd}$ content in $\mathrm{Cd}_{\mathrm{x}} \mathrm{Zn}_{1-\mathrm{x}} \mathrm{O}$ films implanted by $\mathrm{Au}$ ions with ion doses of 5 $\times 10^{14} \mathrm{~cm}^{-2}$ (low) and $5 \times 10^{15} \mathrm{~cm}^{-2}$ (high). For pure $\mathrm{ZnO}$, these two doses correspond to the two distinct damage accumulation stages: gradual accumulation (low dose) and saturation (high dose) in accordance with literature (see, for example, Refs. 8 and 20). It is clearly seen from Fig. 6 that increasing the $\mathrm{Cd}$ content strongly enhances the damage in both sublattices for high dose implantation. In fact, the damage level in $\mathrm{Zn}$ sublattice of high dose implanted $\mathrm{CdZnO}$ increases from 0.55 to 0.87 with increasing of the $\mathrm{Cd}$ content from $0 \%$ to $5 \%$ as clearly seen from Fig. 6 . This damage level $(0.87)$ is much higher than the saturation level for the bulk damage peak in pure $\mathrm{ZnO}$ which is typically $\lesssim 0.5$. However, there is no practically damage enhancement observed for the low ion dose (open symbols in Fig. 6). Furthermore, the implanted ions generate more structural dam- age in the $\mathrm{Cd}$ sublattice than in $\mathrm{Zn}$ sublattice, as it is mentioned above and clearly illustrated by the results shown in Fig. 6.

Comparing the damage accumulation in high and low dose implanted samples in Fig. 6 we conclude that the $\mathrm{Cd}$ content strongly affects the saturation stage of the damage accumulation behavior. Thus, $\mathrm{Cd}$ incorporation in $\mathrm{ZnO}$ decreases the dynamic annealing process during ion bombardment. One of the possible reasons for that is the reduced effective diffusivity of $\mathrm{Cd}$ and/or $\mathrm{Zn}$ interstitials in $\mathrm{CdZnO}$ layers. The displaced $\mathrm{Cd}$ atoms (or $\mathrm{Cd}$ agglomerations) may also act as additional nucleation sites for the defect accumulation and, hence, lead to the damage enhancement in the $\mathrm{Zn}$ sublattice of the $\mathrm{CdZnO}$ layers. Note that the same mechanism may contribute to the damage enhancement in MgZnO. However, due to the low sensitivity of RBS to light atoms it is not possible to estimate the damage in the $\mathrm{Mg}$ sublattice of $\mathrm{MgZnO}$. In addition, the other mechanisms discussed in Sec. III B for enhanced damage accumulation in $\mathrm{MgZnO}$ can be also applied to $\mathrm{CdZnO}$. Furthermore, the observed results indicate that $\mathrm{CdZnO}$ seems to be less resistant to amorphization than both $\mathrm{MgZnO}$ and pure $\mathrm{ZnO}$. Further work is currently pursued to understand the exact role of the $\mathrm{Cd}$ atoms in ion-beam-induced damage formation in $\mathrm{CdZnO}$ layers.

\section{CONCLUSIONS}

In conclusion, we have studied the effect of the film composition on radiation damage accumulation in $\mathrm{MgZnO}$ and $\mathrm{CdZnO}$ relative to that in pure $\mathrm{ZnO}$. The results show that an increase in either the $\mathrm{Mg}$ or $\mathrm{Cd}$ contents results in overall enhancement of radiation induced disorder. However, $\mathrm{MgZnO}$ as well as pure $\mathrm{ZnO}$ exhibit a strong degree of dynamic annealing during implantation and these materials cannot be amorphized even with heavy ion bombardment up to an ion dose of $3 \times 10^{16} \mathrm{Er} / \mathrm{cm}^{2}$. The incorporation of $\mathrm{Cd}$ in $\mathrm{ZnO}$ affects the saturation stage of damage accumulation and $\mathrm{CdZnO}$ layers seem to be less resistant to amorphization compared to $\mathrm{MgZnO}$ or pure $\mathrm{ZnO}$. The observed results may be attributed to: (i) a prominent role of different surface conditions for the interaction with generated point defects in $\mathrm{ZnO}$-based films, relative to pure $\mathrm{ZnO}$; (ii) processes of phase segregation during dynamic annealing; and (iii) enhanced defect accumulation rate for $\mathrm{Cd}$ (presumably also for $\mathrm{Mg}$ atoms) in $\mathrm{W}-\mathrm{ZnO}$-matrix.

\section{ACKNOWLEDGMENTS}

Support from the Norwegian Research Council via FRINAT and RENERGI programs is acknowledged. The international cooperation was partially funded by NordForsk and Chinese Academy of Science.

${ }^{1}$ Ü. Özgür, Ya. I. Alivov, C. Liu, A. Teke, M. A. Reshchikov, S. Doğan, V. Avrutin, S.-J. Cho, and H. Morkoç, J. Appl. Phys. 98, 041301 (2005).

${ }^{2}$ Thin Films and Nanostructures, edited by C. Jagadish and S. J. Pearton (Elsevier, Amsterdam, 2006).

${ }^{3}$ T. Makino, Y. Segawa, M. Kawasaki, A. Ohtomo, R. Shiroki, K. Tamura, T. Yasuda, and H. Koinuma, Appl. Phys. Lett. 78, 1237 (2001).

${ }^{4}$ S. Shigemori, A. Nakamura, J. Ishihara, T. Aoki, and J. Temmyo, Jpn. J. Appl. Phys., Part 2 43, L1088 (2004).

${ }^{5}$ F. Bertram, S. Giemsch, D. Forster, J. Christen, R. Kling, C. Kirchner, and 
A. Waag, Appl. Phys. Lett. 88, 061915 (2006).

${ }^{6}$ Z. L. Liu, Z. X. Mei, T. C. Zhang, Y. P. Liu, Y. Guo, X. L. Du, A. Hallen, J. J. Zhu, and A. Yu. Kuznetsov, J. Cryst. Growth 311, 4356 (2009).

${ }^{7}$ J. L. Morrison, J. Huso, H. Hoeck, E. Casey, J. Mitchell, L. Bergman, and M. G. Norton, J. Appl. Phys. 104, 123519 (2008)

${ }^{8}$ S. O. Kucheyev, J. S. Williams, C. Jagadish, J. Zou, C. Evans, A. J. Nelson, and A. V. Hamza, Phys. Rev. B 67, 094115 (2003).

${ }^{9}$ C. W. White, L. A. Boatner, P. S. Sklad, C. J. McHargue, S. J. Pennycook, M. J. Aziz, G. C. Farlow, and J. Rankin, Mater. Res. Soc. Symp. Proc. 74, 357 (1987)

${ }^{10}$ Z. Q. Chen, M. Maekawa, A. Kawasuso, S. Sakai, and H. Naramoto, J. Appl. Phys. 99, 093507 (2006).

${ }^{11}$ K. Lorenz, E. Alves, E. Wendler, O. Bilani, W. Wesch, and M. Hayes, Appl. Phys. Lett. 87, 191904 (2005).

${ }^{12}$ S. O. Kucheyev, J. S. Williams, J. Zou, and C. Jagadish, J. Appl. Phys. 95, 3048 (2004).

${ }^{13}$ E. Wendler, W. Wesch, E. Alves, and A. Kamarou, Nucl. Instrum. Methods Phys. Res. B 218, 36 (2004).

${ }^{14}$ Despite that $\mathrm{Mg}, \mathrm{Cd}$, and $\mathrm{Zn}$ occupy the same type of lattice sites in wurtzite structure of a ternary alloy, we use the term $\mathrm{Mg}, \mathrm{Cd}$, and $\mathrm{Zn}$ sublattice to distinguish the contributions from different atoms in the damage produced by the ion bombardment in ternary compounds.

${ }^{15}$ K. Schmid, Radiat. Eff. 17, 201 (1973).

${ }^{16}$ J. F. Ziegler, J. P. Biersack, and U. Littmark, The Stopping and Range of Ions in Solids (Pergamon, New York, 1985), Vol. 1, p. 109; www.srim.org
${ }^{17}$ H. M. Naguib and R. Kelly, Radiat. Eff. 25, 1 (1975).

${ }^{18}$ A. M. Mazzone, Phys. Status Solidi A 95, 149 (1986).

${ }^{19}$ D. C. Look, G. C. Farlow, P. Reunchan, S. Limpijumnong, S. B. Zhang, and K. Nordlund, Phys. Rev. Lett. 95, 225502 (2005).

${ }^{20}$ A. Yu. Azarov, S. O. Kucheyev, A. I. Titov, and P. A. Karaseov, J. Appl. Phys. 102, 083547 (2007).

${ }^{21}$ Note that the $\mathrm{Zn}$ depth scale for the MgZnO layers is slightly different from one for the pure $\mathrm{ZnO}$ due to different electronic stopping power in these materials. Thus, in order to minimize errors in the depth scale determination for the $\mathrm{MgZnO}$ films we calculated electronic stopping power using TRIM code (Ref. 16) with the material density calculated by a linear interpolation between the densities of $\mathrm{ZnO}\left(5.6 \mathrm{~g} / \mathrm{cm}^{3}\right)$ and $\mathrm{MgO}$ $\left(3.58 \mathrm{~g} / \mathrm{cm}^{3}\right)$.

${ }^{22}$ Note that it is not obvious how to distinguish between the bulk and surface damage peaks in $\mathrm{Mg}_{0.3} \mathrm{Zn}_{0.7} \mathrm{O}$ because of unimodal damage profile. So for these samples the damage levels were chosen at the depth which corresponds to the maximum of relative disorder of bulk damage peak for pure $\mathrm{ZnO}$ samples implanted to the same ion dose.

${ }^{23}$ C. Ronning, P. X. Gao, Y. Ding, Z. L. Wang, and D. Schwen, Appl. Phys. Lett. 84, 783 (2004).

${ }^{24}$ E. Friedland and M. Hayes, Nucl. Instrum. Methods Phys. Res. B 65, 287 (1992).

${ }^{25}$ E. Wendler, K. Gärtner, and W. Wesch, Nucl. Instrum. Methods Phys. Res. B 266, 2872 (2008).

${ }^{26}$ C. R. A. Catlow and A. M. Stoneham, J. Phys. C 16, 4321 (1983). 